\title{
BEHAVIOUR AND STRENGTH OF HEADED SHEAR STUD CONNECTORS
}

Headed stud shear connectors are commonly used to transfer longitudinal shear forces across the steel-concrete interface in composite structures. This paper is focused on the experimental and numerical study on the behaviour of this type of connectors. The push-out tests of headed studs, $10 \mathrm{~mm}$ in diameter and $50 \mathrm{~mm}$ in length, in normal C25/30 concrete with transverse reinforcement were carried out. The experimental study also treated the influence of the connectors spacing, in the longitudinal and transversal directions, and the thickness of the concrete slab on the shear resistance.

Keywords: Shear connectors, shear resistance, finite element analysis, push-out test.

\section{Introduction}

Headed stud shear connectors are the most widely used shear connectors in steel-concrete composite structures. The most important characteristics for the design of the composite structures are the shear capacity and the load-slip relations of these connectors. The most exact method to determine these characteristics is a fullscale composite beam test but it might be time-consuming and costly, therefore the push-out tests are adopted.

In the second half of the 20th century, the first parametric studies to investigate the behaviour of the connectors were realized. The first analysis of headed stud connectors with different parameters was carried out by Viest [1], followed by Slutter and Driscoll [2] and [3], Goble [4]. The behaviour of connectors was analysed by the authors in [5][6][7]. Lam and El-Lobody [8] developed a numerical model of push-out tests, which they compared to the experimental results and the design standards - British BS5950 [9], European EC4 [10] and American AISC [11]. Design of the connection in the composite structures according to EC4 is described also in [12].

However, the full-scale push-out test remains also the timeconsuming and costly option, therefore the numerical analysis is adopted, once the verification of the numerical model with experimental results was established.

The main objective of this investigation is to carry out the fullscale push-out tests and to develop a three-dimensional finite element model using the software ATENA to simulate the behaviour of headed shear stud connectors and to use it for subsequent parametric study. The results of this model were compared with the experimental results. The push-out tests with different configurations of connectors, $10 \mathrm{~mm}$ in diameter and $50 \mathrm{~mm}$ in length, in normal C25/30 concrete with transverse reinforcement were carried out.

\section{Push-out test specimens}

Five series of three push-out specimens called SP1, SP2, SP3, SP4 and SP5, were tested (Fig. 1). Each specimen consists of a short piece of steel beam HEB 260 connected on both sides to concrete slabs using shear connectors. The concrete slabs dimensions are $650 \mathrm{~mm}$ length and $600 \mathrm{~mm}$ width for all the specimens. However, the thickness of the specimen SP1 $(150 \mathrm{~mm})$ is different from that of specimens SP2 to SP5 $(100 \mathrm{~mm})$. Concrete slabs were produced from concrete $\mathrm{C} 25 / 30$. For each mix, three cylindrical specimens of concrete were prepared and tested to obtain the concrete strength. The connectors are made of steel S235J2. The specimens SP1SP2 are realized with four connectors and the specimens SP3-SP5 with six connectors welded on each beam flange. The diameter of the connectors is $10 \mathrm{~mm}$ and their height $50 \mathrm{~mm}$. The longitudinal distance between the connectors is $250 \mathrm{~mm}$ (SP1-SP2), $60 \mathrm{~mm}$ (SP3, SP5) or $40 \mathrm{~mm}$ (SP4) and transversal distance is $100 \mathrm{~mm}$ (SP1-SP4) and $32 \mathrm{~mm}$ (SP5).

Slip between the concrete slabs and the steel beam is measured continuously using potentiometric displacement transducers. The average value of slip between the two interfaces concrete-steel is plotted against the load per connector and used to compare the different configurations. Fig. 2 shows the tested configurations of push-out specimens.

\footnotetext{
* Patricia Duratna ${ }^{1,2}$, Jan Bujnak ${ }^{1}$, Abdelhamid Bouchair ${ }^{2}$, Frantisek Bahleda ${ }^{1}$

${ }^{1}$ Department of Structures and Bridges, Faculty of Civil Engineering, University of Zilina, Slovakia, E-mail: patricia.duratna@fstav.uniza.sk, patricia.duratna@polytech.univ-bpclermont.fr

${ }^{2}$ Clermont Université, Université Blaise Pascal, Institut Pascal, Clermont-Ferrand, France
} 


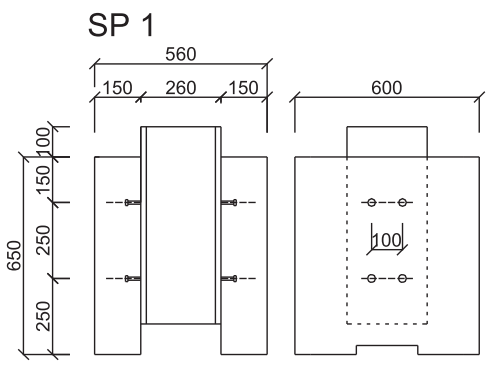

SP 4

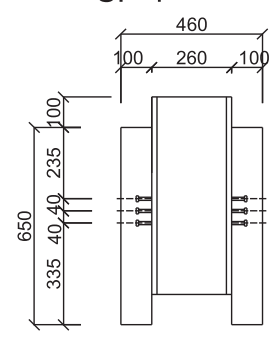

SP 2
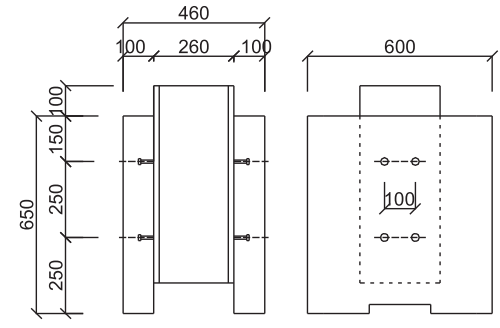

SP 5
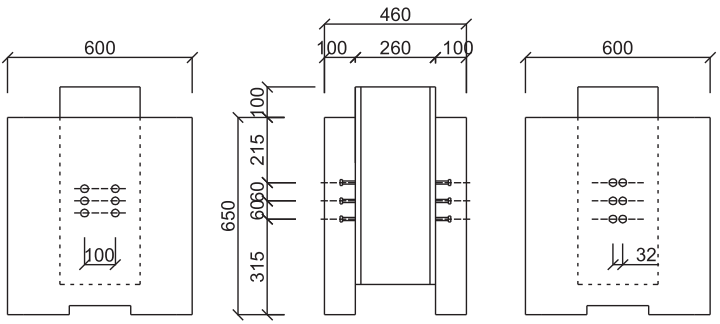

Fig. 1 Details of the push-out test specimens

The procedure of testing was carried out in accordance with Eurocode 4 [10]. The load was applied in increments from 0 to $40 \%$ of the expected failure load, and then returned to $5 \%$ of the expected failure load. After that, the loading cycle between the values of 5 and $40 \%$ was repeated 25 times. The slip controlled load continued up to the failure so that it did not occurred earlier than in 15 minutes. At each load increment, values of slip between the steel beam and the concrete were recorded. For each specimen, 8 transducers ( 4 for each steel-concrete interface) were used to measure the relative displacement, vertical displacement between steel and concrete, representing the slip, and 4 ( 2 for each steelconcrete interface) to measure the horizontal displacement representing the separation between steel and concrete.

\section{Finite Element Model}

Finite element (FE) model is developed using the software ATENA. It considers the nonlinear behaviour of materials and the large displacements. It is capable of simulating real behaviour of concrete material in structures including cracking, crushing and reinforcement yielding.

\subsection{Finite Element Mesh}

Three-dimensional linear four-node tetrahedral isoparametric element (IsoTetra4_3D) was used to model the specimens. Because of symmetry, only a quarter of the push-out configuration was modelled. Fig. 3 shows the FE mesh used to represent a quarter of the push-out test specimen. The element size is $0.05 \mathrm{~m}$ for the elements of concrete slab and steel beam and $0.005 \mathrm{~m}$ for the shear connectors (head and shank). The circular shape of the connec- tor is approximated by a prism because of the problems with concentrated mesh in cylindrical form of the stud.

\subsection{Boundary Conditions}

To reproduce the testing conditions on the supports, all the nodes of the concrete slab on the opposite side of loading are fixed in the $\mathrm{Z}$ direction. All the nodes on the plane of symmetry of the specimen (steel beam web and bearing plate) are fixed in the $\mathrm{X}$ direction. For the second plane of symmetry (XZ), all the nodes of concrete, steel beam flange and steel beam web are fixed in the $\mathrm{Y}$ direction.

\subsection{Application of the Load}

A displacement controlled load is applied at the centre of the steel web, as shown in Fig. 3. Load is applied using the arc length method to improve the convergence process in the phases of large nonlinearities. An initial increment of displacement is given on the data line and the initial load proportionality factor is assigned to this initial increment using the automatic incremental scheme.

\subsection{Materials behaviour}

To describe the behaviour of the concrete slab in the push-out specimen, concrete is treated as an elastic-plastic material, as shown in Fig. 4a. From tests realized on cylinder specimens, the average measured value compressive strength $\left(f_{c u}^{\prime}=28 \mathrm{MPa}\right)$ was set-up and entered as known input concrete property and the other values have been calculated according to the parameters used by ATENA: 


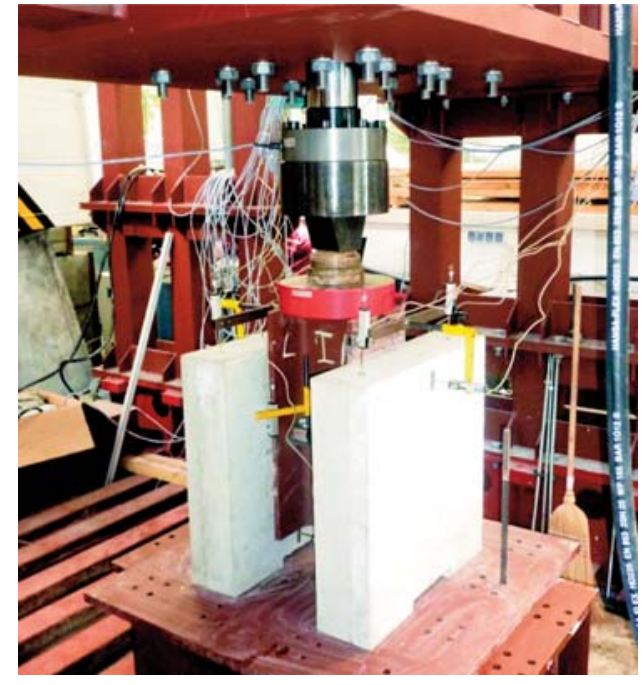

Fig. 2 Configuration of the push-out test

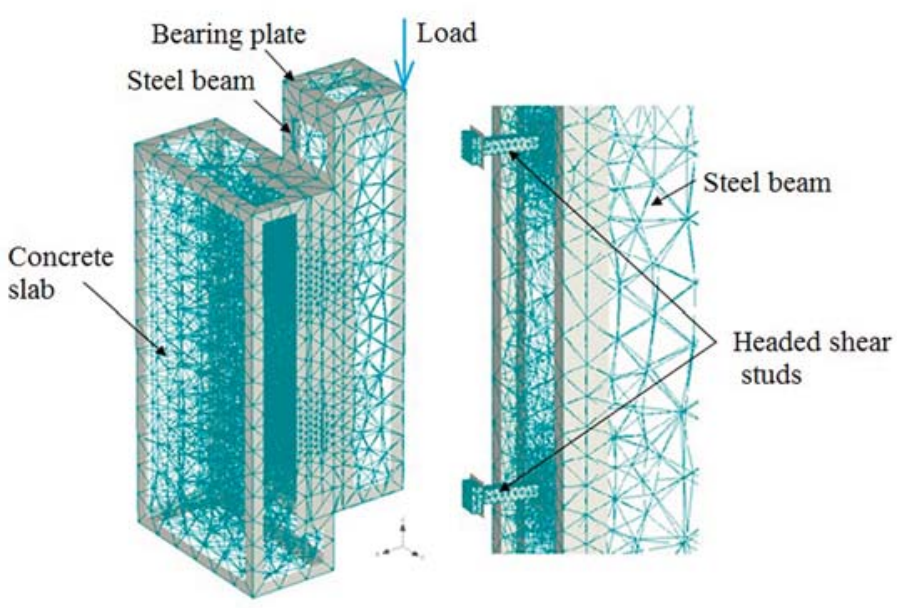

Fig. 3 Finite element mesh of the model

$$
\begin{aligned}
& f_{c}^{\prime}=0.85 f_{c u}^{\prime} ; f_{t}^{\prime}=0.24 f_{c u}^{\prime 2 / 3} ; \\
& \left.E_{c}=\left(6000-15.5 f_{c u}^{\prime}\right)\right) \overline{f_{c u}^{\prime}}
\end{aligned}
$$

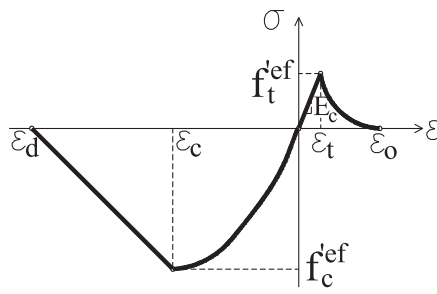

a)

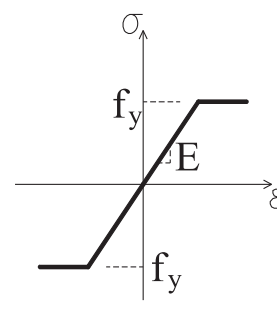

b)
Fig. 4 Stress-strain law for (a) concrete; (b) steel beam, headed stud and reinforcement

The stress-strain curve of the headed stud is shown in Fig. 4b. The steel was modelled as elastic perfectly plastic. For stud and beam, the Young's modulus $E=210000 \mathrm{MPa}$ is chosen and the yield stress is taken equal to $f_{y}=360 \mathrm{MPa}$ for stud and to $f_{y}=$ $=235 \mathrm{MPa}$ for the steel beam. For the steel reinforcement, the Young's modulus and yield stress chosen are: $E=200000 \mathrm{MPa}$ and $f_{y}=550 \mathrm{MPa}$, respectively. Reinforcement was modelled by discrete bars loaded in tension and also in compression.

\section{Results}

Because of limited number of specimens the evaluation was not carried out statistically, but the characteristic resistance $P_{R k}$ and the characteristic ultimate slip $\delta_{u k}$ were determined in accordance with [10]. These values are presented in Table 1 . The value $P_{u, \min }$ is the value of minimal failure load, the characteristic resistance $P_{R k, \text { exp }}$ is $0.9 P_{u, \text { min }}$ and $\delta_{u k}$ is the maximal value of the slip measured at characteristic load. From these results, according to the Eurocode 4 requirements [10], it can be observed that the $10 \mathrm{~mm}$ studs tested with concrete $\mathrm{C} 25 / 30$ cannot be considered as ductile $\left(\delta_{u k}<6\right.$ $\mathrm{mm}$ ). The failure modes observed were the shear failure of the studs or the combination of failures of stud and concrete bearing. The typical failures are shown in Fig. 5.

Table 1

\begin{tabular}{|c|c|c|c|}
\hline \multirow{2}{*}{ Series } & \multicolumn{2}{|c|}{ Strength per stud $[\mathrm{kN}]$} & Ductility $[\mathrm{mm}]$ \\
\cline { 2 - 4 } & $P_{u, \text { min }}$ & $P_{R k, \text { exp }}$ & $\delta_{u k}$ \\
\hline SP1 & 31.91 & 28.71 & 4.5 \\
\hline SP2 & 29.48 & 26.53 & 4.4 \\
\hline SP3 & 33.29 & 29.96 & 4.7 \\
\hline SP4 & 29.64 & 26.67 & 4.1 \\
\hline SP5 & 34.09 & 30.68 & 5.9 \\
\hline
\end{tabular}

Figure 6 shows the mean force-slip curves for all the specimens taking into account the force corresponding to one connector. It can be observed that for all the tested configurations of push-out specimens, in the elastic domain, the behaviour of the studs is characterized by very close values of initial stiffness. When curves exceed the initial domain, a plastic plateau can be observed for the specimens SP1, SP3 and SP4. For the other specimens (SP2 and SP5), the plastic plateau is too short and passes directly to the decreasing branch. From Fig. 6 and Table 1, it can be stated that the resistance and ductility of $10 \mathrm{~mm}$ stud is not influenced by the 


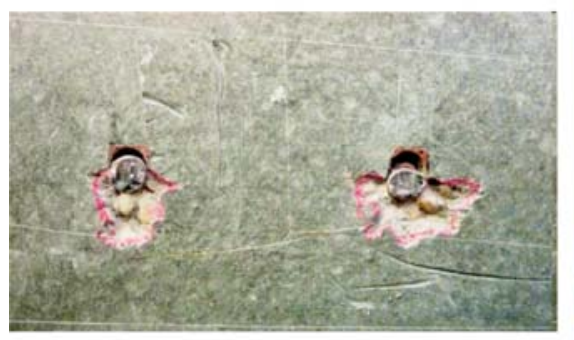

0
50

$100 \mathrm{~mm}$

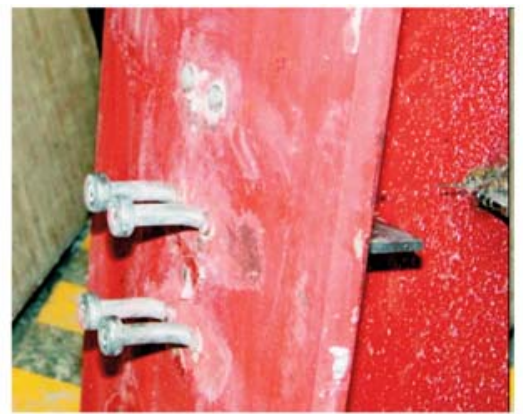

0
50
$100 \mathrm{~mm}$

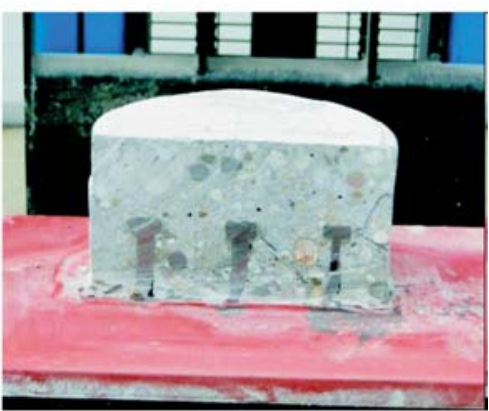

$0 \quad 50 \quad 100 \mathrm{~mm}$

Fig. 5 Details of failures of the push-out test specimens

slab thickness, the longitudinal and transversal spacing of the connectors. However, for the SP1 specimen, where the transversal spacing is limited to $32 \mathrm{~mm}$, the resistance and ductility of the stud is greater than the others with larger spacing. As the value of $32 \mathrm{~mm}$ is in the limit of the Eurocode 4 [10], it is supposed that it is caused by the proximity of the studs to the web of the steel beam where the stiffness is greater.

Fig. 6 shows also a comparison between the load-slip curves obtained experimentally and numerically using the finite element method. The model describes well the elastic domain of the stud; however for plastic domain it does not represent the descending branch of force-slip curve. This one could be explained by the damage evolution in the concrete or the connector welded basis.

Eurocode 4 specifies for the studs with $16-25 \mathrm{~mm}$ diameters two expressions (2) to determine their strength:

$$
P_{R k, 1}=0.8 f_{u} \pi d^{2} / 4 \quad P_{R k, 2}=0.29 d^{2} \sqrt{f_{c k} E_{c m}}
$$

With the nominal values of steel and concrete, the calculated resistances (without the partial safety factor) of the tested connectors are: $P_{R k, 1}=32.04 \mathrm{kN}$ and $P_{R k, 2}=25.53 \mathrm{kN}$.

\section{Conclusion}

The behaviour of shear studs $(d=10 \mathrm{~mm}, h=50 \mathrm{~mm})$ with concrete $\mathrm{C} 25 / 30$ is analysed on the basis of 15 push-out tests. The tests showed insufficient ductility of these connectors, with slip lower than $6 \mathrm{~mm}$, for all the configurations. The tests showed also a small influence of the slab thickness and transversal and longitudinal spacing of the studs on their resistance and ductility. A finite element model is developed to simulate the behaviour of the studs considering the nonlinear behaviour of materials (steel and concrete). The proposed model described well the behaviour of the tested specimens mainly in the elastic domain. Improvements of the model are in progress to represent the whole load-slip curves of the push-out test including the descendant branches.

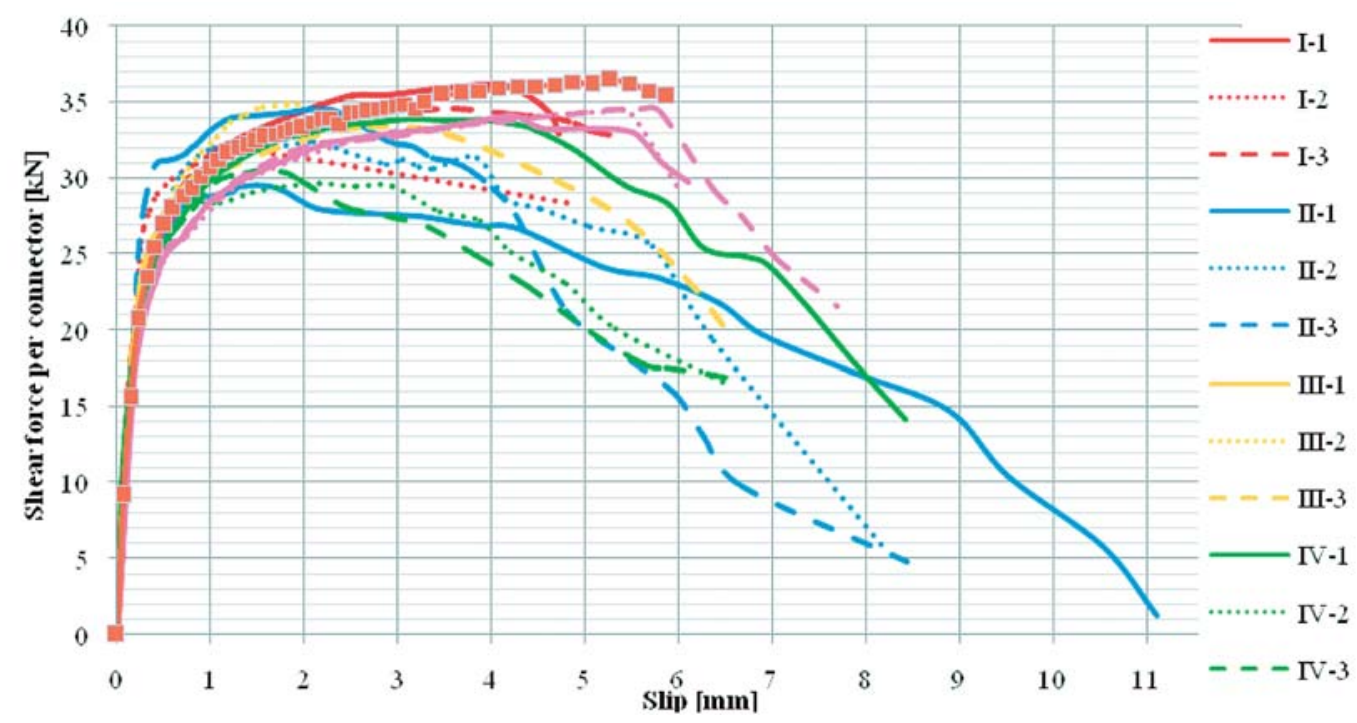

Fig. 6 Load-slip curves of the push-out tests 


\section{References}

[1] VIEST, I. M.: Test of Stud Shear Connectors - Parts I, II, III and IV, Engrg. Test Data, Nelson Stud Welding. Lorain, Ohio, 1956.

[2] SLUTTER, R. G., DRISCOLL, G. C.: Flexural Strength of Steel-concrete Composite Beams. J. of the Structural Division, ASCE, No. 2, vol. 91, April 1965, pp. 71-99.

[3] DRISCOLL, G. C., SLUTTER, R. G.: Research on Composite Design. Proc. of National Engineering Conference, Lehigh University, AISC, May, 1961.

[4] GOBLE, G. G.: Shear Strength of thin Lange Composite Specimens. Engineering J., AISC, No. 2, vol. 5, 1968. pp. 62-65.

[5] BUJNAK, J., FURTAK, K., ODROBINAK, J.: On Shear Connection Design in Composite Beams. Communications - Scientific Letters of the University of Zilina, 2002, No. 3, vol. 4, p. 13-16.

[6] ODROBINAK, J.,JUTILA, A.: Longitudinal Shear Flow at the Support Srea of Beam with an Overhanging Cantilever, Communications - Scientific Letters of the University of Zilina, 2002, No. 3, vol. 4, p. 17-20.

[7] BUJNAK, J., FURTAK, K.: Research on Shear Connection Design in Composite Beams. Communications - Scientific Letters of the University of Zilina, 2007, No. 3, vol. 9, p. 47-50.

[8] LAM, D., EL-LOBODY, E.: Behavior of Headed Stud Shear Connectors in Composite Beam. J. of Structural Engineering, ASCE, January 2005, pp. 96-107.

[9] British Standards Institution. Code of Practice for Design of Simple and Continuous Composite Beams. BS5950, Part 3: Section 3.1 Structural use of steelwork in building. London, 1990.

[10] CEN.Eurocode 4: Design of Composite Steel and Concrete Structures, Part 1: General rules and rules for building. Brussels: CEN, 2006.

[11] American Institute of Steel Construction: Load and Resistance Factor Design Specification for Structural Steel Building, Chicago, 1999.

[12] DURICOVA, A., ROVNAK, M.: Design of Composite Steel and Concrete Structures According to STN EN 1994-1-1, VEDA, Bratislava, 2008. 